\title{
Portugal e Brasil no Cenário da saúde mental ${ }^{\star}$
}

\author{
Raquel Siqueira-Silva, $\star \star$; João Arriscado Nunes ${ }^{I}$; Marcia Moraes ${ }^{I I, \star \star \star ~}$ \\ ${ }^{I}$ Centro de Estudos Sociais-Universidade de Coimbra-Portugal; \\ ${ }^{I I}$ Universidade Federal Fluminense, Niterói, RJ - Brasil
}

\section{Resumo}

Este artigo visa discutir os modelos de atuação no campo da saúde mental em Portugal, estabelecendo algumas distinções por relação aos referenciais que norteiam a saúde mental no Brasil. Nota-se que enquanto no Brasil a saúde mental foi marcada pela Reforma Psiquiátrica, com inspiração italiana, em Portugal a saúde mental segue a referência da Psiquiatria de Setor. Foram realizadas quatro entrevistas semiestruturadas com profissionais e familiares portugueses. O texto conclui com a indicação de que em Portugal a Psiquiatria de Setor ainda não atingiu integralmente sua proposição de atendimento comunitário.

Palavras-chave: Saúde Mental, Reforma Psiquiátrica, Psiquiatria de Setor.

\section{Portugal ANd Brazil in the SCENario of Mental health}

\begin{abstract}
This article aims to discuss the intervention models in the field of mental health in Portugal, establishing distinctions based on Brazil mental health references. It is underlined that while mental health in Brazil was marked by the Psychiatric Reform, guided by italian model, in Portugal mental health is following the reference of Sector Psychiatry. There were four semi-structured interviews with professionals and Portuguese patiente relatives. The text concludes with the statement that in Portugal the Sector Psychiatric has not yet reached its full proposition of community care.
\end{abstract}

Keywords: Mental Health; Psychiatric Reform; Sector Psychiatric.

^ Este artigo está baseado em tese de doutorado intitulada Grupos Musicais em Saúde Mental: conexões entre Brasil e Portugal (SIQUEIRA-SILVA, 2012). Os fragmentos do campo colhidos em Portugal foram possíveis por estágio doutoral no Centro de Estudos Sociais da Universidade de Coimbra, realizado de maio a outubro de 2011. Temos autorização expressa dos entrevistados para a publicação de seus nomes originais. Esta pesquisa contou com o apoio da CAPES.

$\star \star$ Bolsista no Programa Ciências sem Fronteiras, Pós-doutorado.

$\star \star \star$ Endereço para correspondência: Marcia Moraes. Campus do Gragoatá - Rua Professor Marcos Waldemar de Freitas Reis, Bloco O, sala 214 - CEP 24210-201 - São Domingos - Niterói RJ-Brasil.E-mail: raquelsiqueira13@gmail.com, jan@ces.uc.pt,mazamoraes@gmail.com. 
A loucura não é um fato de natureza mas de cultura, e sua história é a das culturas que a dizem loucura e a perseguem. (ROUDINESCO, 1994, p.15)

\section{INTRODUÇÃo}

O objetivo do presente trabalho é apresentar algumas considerações acerca dos modelos de saúde mental em Portugal e no Brasil. Estes dois países adotam posturas diferentes no que toca ao campo da saúde mental, embora seja possível reconhecer em ambos as críticas ao modelo manicomial. Ao longo do texto são apresentados extratos de quatro entrevistas semiestruturadas realizadas com profissionais da área e com familiares de usuários.

No século XIX há uma produção de "olhar científico sobre o fenômeno da loucura e sua transformação em objeto de conhecimento: a doença mental" (AMARANTE, 1995, p. 24). Neste período surgiram as instituições que atualmente identificamos como hospitais psiquiátricos, com as prerrogativas de tratar e/ou educar e/ou isolar os usuários de serviços de saúde mental. "A proliferação dos asilos ocorreu no século XIX, um pouco por toda a Europa" (ALVES, 2011, p. 33). Estes dispositivos de tratamento estavam associados a um discurso protecionista, em que o usuário seria protegido se estivesse afastado do convívio social. Ao mesmo tempo, isto servia a "resguardar" a população de alguma periculosidade intrínseca atribuída a estas pessoas. Mas esses dispositivos foram desde cedo objeto de críticas.

Os hospitais psiquiátricos foram tomados como um recurso catalisador das soluções ao problema da loucura. O asilamento e os modos de tratamentos coercitivos, disciplinadores, organicistas, não foram suficientes para que os usuários conquistassem a liberdade do convívio social. O modelo manicomial era e é uma máquina de produção e reprodução desta loucura segregada. Sem lugar para a "desrazão", as possibilidades de racionalidades surgem como mecanismos de controle. Alguns discursos médico-científicos respaldavam e ainda respaldam estas instituições e agregam actantes ${ }^{2}$ para justificar o exílio como tratamento, como se isto fosse capaz de suprir as necessidades de vida e saúde.

Como desconstruir o modelo manicomial? Como inserir socialmente os utentes? $?^{3}$ A psiquiatria toma para si esta incumbência e várias iniciativas pós II Guerra Mundial a fortalecem.

A Psiquiatria Social afirma-se sobretudo a partir da II Guerra Mundial, com as Comunidades Terapêuticas, a Psiquiatria de Setor, a Psicoterapia Institucional e a Psiquiatria Comunitária e de Higiene Mental. As respostas tradicionais (asilos e hospitais psiquiátricos), além de contestadas, já não são suficientes para dar resposta às necessidades, visto que com o pós-guerra o número de pessoas com problemas psiquiátricos aumenta. (MELO apud ALVES, 2011, p. 37). 
Na década de 1960 surgem as críticas ao modelo manicomial e seus modos de tratamento, configurando um enfoque político-revolucionário. Isto desestabilizou as estruturas das crenças manicomiais. O hospital psiquiátrico centralizador começou a ser burilado pelas ideias e ideais reformistas. Os pensamentos de Goffman $(2001)^{4}$ e de Foucault $\left(2005^{5}\right.$ e 2004) ${ }^{6}$ dentre outros, influenciaram esta nova perspectiva. Defendia-se a liberdade, os direitos e melhores tratamentos. Basaglia (2001) ${ }^{7}$ tratava a questão de modo a prescindir do manicômio. Estes pensadores lançaram algumas centelhas para explodir os muros manicomiais, mas estes muros não seriam somente os concretos que cercavam as construções, mas os modos de lidar com os usuários dos serviços. A proposta era, em suma, modificar a relação mais imediata entre as pessoas e proporcionar um atendimento digno, com procedimentos terapêuticos mais adequados. Eram os primeiros movimentos para a desinstitucionalização.

Em meados dos anos 1950, o desenvolvimento da psicofarmacologia mobilizou o campo psiquiátrico,

[...]suprimindo os sintomas mais perturbadores e tornando muitos doentes acessíveis à psicoterapia e ao aconselhamento, permitindo repensar as questões de saúde mental de forma diferente e condicionando o próprio desenvolvimento da psiquiatria comunitária. (HESPANHA, 2010, p. 138).

A entrada destes medicamentos no cenário não diminuiu a perspectiva de internação, mas dava a ilusão de já ampliar as possibilidades nos tratamentos. Estes novos actantes mobilizaram as redes deslocando os procedimentos adotados, ainda na forma de contenção medicamentosa, porém menos mecânica e mais capaz de responder às circunstâncias de vida dos pacientes fora da instituição asilar. "Outros estudos no âmbito da prevenção primária dos distúrbios mentais, desenvolvidos também na década de 1960, perspectivam a família como centro da investigação e apelam não só a factores biológicos, mas também psicossociais e socioculturais". (CAPLAN apud ALVES, 2011, p. 38).

Vários fatores foram importantes nos processos de desinstitucionalização e estes efeitos repercutem até a atualidade. Os movimentos para desinstitucionalizar os usuários/utentes agregam muitos interesses e interessados. Para pensar e processar a desconstrução dos asilos manicomiais, enfraqueceram-se algumas articulações, mobilizaram-se micropoderes, agenciaram-se insatisfações de familiares, de usuários e de profissionais. Outros actantes se associam às redes para produzirem esta implosão do modelo hospitalocêntrico.

Os ideais da desinstitucionalização contra o modelo manicomial ressoaram em muitos países, com suas diferenças culturais, sociais, econômicas, políticas, dentre outras. Em Portugal repercutiu a Psiquiatria de Setor. Suas bases surgiram na política norte-americana centrada no Community Mental Health Center (CMHC), cujas características fundamentais eram: "a continuidade de cuidados, a facilidade de acesso sem discriminação, o controlo e a implicação da comunidade e a responsabilidade especificamente geográfica". (BAERT apud ALVES, 
2011, p. 38-39). A proposta seria então a de implicar a comunidade, iniciativa importante à inserção social, com a prerrogativa de atendimento que não prescindia do hospital psiquiátrico, porém, vislumbrava o tratamento além dele.

Esta orientação de assistência nos EUA desenvolveu-se também na Europa - a psiquiatria de sector -, inicialmente a partir da França, mas expandindo-se rapidamente para outros países. Este movimento transformou-se, nos anos 1960, em política oficial de muitos países, incluindo Portugal. (ALVES, 2011, p. 39).

Ratificava-se a inoperância de um modelo centrado no hospitalocentrismo psiquiátrico. As ideias sobre a inserção social associavam-se a necessidade de se implementar modelos mais adequados de atendimento e mais próximos das localidades de moradia dos utentes. "O objetivo era o de aliar a psiquiatria à comunidade evitando ao máximo a segregação e o isolamento do doente" (ALVES, 2011, p. 39). Esta vertente estava agregada ao conhecimento e poder psiquiátricos, não era compartilhada com os utentes. Mas as prerrogativas e seus objetivos sob o domínio dos profissionais visavam à melhoria do atendimento.

Podemos sintetizar dois objetivos básicos que a psiquiatria de sector preconiza: o primeiro seria o de prestar assistência precoce aos doentes mentais e apoiar os doentes crónicos não só a nível médico, mas também social; o segundo seria o de evitar a desadaptação provocada pelo afastamento do doente em relação ao seu meio, promovendo para este fim a criação de estruturas a nível da comunidade e evitando a hospitalização. (ALVES, 2011, p. 39).

A preocupação em tratar sem desnecessariamente hospitalizar era uma premissa. Embora este procedimento fosse de domínio médico, a comunidade começava a entrar no cenário. Estavam em voga outros actantes conectados aos tratamentos para inserir o usuário no convívio social e enfraquecer a segregação.

Os seus defensores postulam que qualquer terapia jamais será bem sucedida no interior de uma estrutura hospitalar excluidora e despersonalizante. Preconiza-se que o doente seja tratado no seu meio, junto com a sua família e outros grupos (através de instituições extra-hospitalares: póscura, ambulatório, etc.), de modo a promover a aceitação e integração social do doente mental, em vez da sua exclusão. (FLEMING apud ALVES, 2011, p. 39).

O hospital psiquiátrico não é somente o responsabilizado no tratamento. $\mathrm{O}$ convívio social é considerado como relevante na recuperação do utente. Instaura-se o discurso da inclusão social conectado à desinstitucionalização. 


\section{Em Portugal: Psiquiatria de Setor}

Em 1963 Portugal oficializa sua preocupação com a desinstitucionalização e preconiza um modelo adequado de atendimentos aos utentes de saúde mental no país.

Portugal acolheu a filosofia da desinstitucionalização relativamente cedo, com a aprovação, em 1963, de uma lei de Saúde Mental, sem que, no entanto, se tenha verificado, como em outros países, uma discussão acalorada sobre o tema ou o surgimento de movimentos anti-manicomiais. A psiquiatria seguia mais a psiquiatria de sector e, por isso, o modelo italiano de Basaglia teve pouca influência. (HESPANHA, 2010, p. 139).

Hespanha observa que esta lei teve pouca repercussão, mobilizou apenas alguns profissionais não-médicos e não alterou a proposta hospitalar em franca atividade. "Esta lei foi inspirada na Psiquiatria de Sector Francesa. Mas na prática, ela não foi implementada, ou melhor, a sua implementação ficou comprometida em vários períodos, apesar de sucessivamente legislada". (ALVES, 2011, p. 49).

Sob o olhar de um dos profissionais entrevistados,

"Houve uma influência da psiquiatria de setor em França. A partir dos anos 60/70/80 teve influência a setorização, a psiquiatria de setor. Alguns psiquiatras portugueses foram influenciados pelas formações em França. Pós- Guerra em França, centra na ideia de que não é fechar o hospital, mas é de que ele seja um dos componentes. [...] Constituir uma equipe multidiscliplinar. Concentrar serviços numa determinada área geográfica, chamou isto de setor, setorização. Há o hospital psiquiátrico e outras unidades. Diferenciadas mas articuladas. Centros de saúde, lares abrigados, centros pós-cura, centros de convivência. O setor passa a ser a entidade que é o centro. Lei de Saúde Mental foi aprovada em 1963, é uma cópia do que aconteceu em França. Foram apenas construídas algumas unidades em número insuficiente. Chegou a haver trinta centros de saúde mental, mas foi insuficiente porque faltaram outras estruturas e os centros sempre tiveram muita dificuldade, falta de recursos materiais e humanos" (José Morgado, ${ }^{8}$ entrevista em 15/06/2011, Coimbra).

As tentativas de reforma no campo da assistência psiquiátrica ocorreram durante um período histórico marcado por mobilizações sociais e políticas com consequências para a sociedade e Saúde em geral. O acontecimento decisivo foi a queda de uma ditadura que durou mais de quatro décadas, e que abriu um processo revolucionário que, apesar da sua curta duração (19741976), transformou profundamente a sociedade portuguesa e influenciou a subsequente "normalização" democrática. 
A queda do regime ditatorial ocorreu sem grandes resistências, o governo português se organizou para um Estado democrático e livre.

A formulação do direito à saúde na nova Constituição de 1976 previa a criação de um Serviço Nacional de Saúde, público, universal e gratuito, que abrangeria a saúde mental. Em revisão constitucional realizada em 1989, foi introduzida uma pequena palavra que, de fato, veio a transformar o Serviço Nacional de Saúde num serviço com pagamento, diferenciado em função da renda, da condição de aposentado, ou de portador de certas doenças crônicas. Essa palavra é "tendencialmente". O acesso à saúde passou a ser "tendencialmente gratuito", e não "gratuito", como declarava a Constituição de 1976 (PORTUGAL, 1976, Constituição da República Portuguesa, art. $64^{\circ}$ ). As taxas moderadoras, introduzidas inicialmente com o intuito declarado de "moderar" o recurso aos serviços públicos de saúde - ou seja, de levar as pessoas a recorrerem menos aos serviços em situações em que estes e os seus agentes consideravam esse recurso desnecessário, como é o caso de atendimentos em serviços de urgência -, transformou-se em pagamento, uma parcela crescente dos custos da atenção em saúde.

Ao longo desse processo, o que sucedeu no domínio da saúde mental?

A perspectiva preconizada pela psiquiatria de setor segue em seu percurso ancorando-se prioritariamente na criação de leis, o que no campo de ações teve pouca ressonância. Os hospitais psiquiátricos ainda ocupavam o lugar central dos tratamentos em saúde mental.

Em 1976, um documento elaborado pelo IAP $^{9}$ e por um grupo de trabalho da zona Centro avaliava assim a situação dos serviços de saúde mental: 'os Serviços de Saúde Mental, como tal, isto é, orientados para a promoção da saúde e não apenas para o tratamento da doença, têm sido entre nós, praticamente inexistentes. Os serviços do IAP praticam em regra uma psiquiatria passiva, centrada no médico, que ainda alheio a todo o tipo de trabalho em equipa vem actuando dentro de uma pseudo auto-suficiência centralizadora, quer nos dispensários quer nas grandes unidades hospitalares psiquiátricas, onde, por consequência, se vão acumulando os alienados' (IAP apud ALVES, 2011, p. 50).

As críticas dos trabalhadores de saúde mental em campo denunciavam que as leis adotadas não refletiam nas práticas. Se a proposta da Psiquiatria de Setor era uma atuação descentralizada, voltada para atendimentos locais, o que acontecia era o tratamento ancorado na figura do médico, o que comprometia a proposta de trabalho em equipe. Os grandes hospitais psiquiátricos eram o suporte deste modo de funcionamento. $\mathrm{O}$ hospital serviria às unidades de serviços, mas estas seriam distribuídas pelo território. Não se propunha acabar com os hospitais psiquiátricos, mas descentralizar o atendimento, diferentemente do que aconteceu com a Reforma Psiquiátrica Italiana que repercutiu no Brasil. 
Com a criação do Serviço Nacional de Saúde em 1979 (VIANA, 2010, p. 74), algumas iniciativas voltaram-se para o campo da saúde mental na perspectiva da setorização. Um dos objetivos era fazer com que os serviços chegassem às comunidades. Evidenciam-se os esforços organizados para atendimento comunitário a toda a população. É criado, em 1979, o Serviço Nacional de Saúde.

\begin{abstract}
A Lei n. ${ }^{\circ}$ 56/79, de 15 de Setembro, cria o Serviço Nacional de Saúde [...] para assegurar o direito à protecção da saúde, nos termos da Constituição. O acesso é garantido a todos os cidadãos, independentemente da sua condição económica e social, bem como aos estrangeiros, em regime de reciprocidade, apátridas e refugiados políticos. OSNS envolve todos os cuidados integrados de saúde, compreendendo a promoção e vigilância da saúde, a prevenção da doença, o diagnóstico e tratamento dos doentes e a reabilitação médica e social. Define que o acesso é gratuito, mas contempla a possibilidade de criação de taxas moderadoras [...] estruturase numa organização descentralizada e desconcentrada, compreendendo órgãos centrais, regionais e locais, e dispondo de serviços prestadores de cuidados de saúde primários (centros comunitários de saúde) e de serviços prestadores de cuidados diferenciados (hospitais gerais, hospitais especializados e outras instituições especializadas). (PORTUGAL, 2010, online).
\end{abstract}

Em saúde mental, a promulgação da lei acima citada prevê a oferta um atendimento adequado que não prescinde da hospitalização. O objetivo é tratar o utente, mas a internação não é descartada, não é preterida.

Qual seria a amplitude da descentralização proposta, já que o domínio do modelo biomédico, a ausência do trabalho em equipe e a manutenção dos hospitais psiquiátricos se mantinha?

Em saúde mental, as tentativas incentivadas pela criação de leis continuavam. A inserção social dos usuários, contudo, só seria possível se estas fossem implementadas.

No período entre 1984 e 1990, a Lei de Saúde Mental (LSM) foi retomada e revista. Neste período, as mudanças propostas tiveram afinidades com o modelo seguido no Brasil. O sentido de descentralização ganha reforços. As complementações da LSM incluem "a criação de uma rede de serviços comunitários, [...] o incremento de unidades de psiquiatria em hospitais gerais, o desenvolvimento de programas de reabilitação e desinstitucionalização de doentes crônicos e o estabelecimento de cooperação com instituições privadas" (ALVES, 2011, p. 50). Reconhece-se aí uma diferença do modelo brasileiro: os serviços são desde o início compartilhados com as corporações privadas. As críticas encontradas na bibliografia consultada e também presentes nas entrevistas com os profissionais apontam algumas dificuldades para implementação destas leis, despachos e decretos nas práticas dos serviços: 
Este é um período em que sucessivas legislações novamente definem a aproximação da psiquiatria à comunidade pela desinstitucionalização e integração dos cuidados. As proliferações destas determinações legais é esclarecedora sobre a sua não implementação na prática, apesar de (e por isso) sucessivamente legislada. (ALVES, 2011, p. 50).

Várias leis foram criadas com o intuito de fazer valer o que um grupo acreditava ser o modo de atendimento mais adequado. Porém, não aconteceu a adesão, mesmo que conflituosamente, da ideia descentralizadora. Não houve o contágio amplo desta ideia entre profissionais, familiares e utentes dos serviços. As conexões que se agenciaram não produziram a tão almejada descentralização. Mas algumas modificações se processaram, valendo a pena destacar as seguintes:

A integração da saúde mental nos serviços de saúde foi finalmente decidida em 1992. O decreto-lei n. 127/92, de 03 de Julho, extinguiu os centros de saúde mental e os centros de saúde mental infanto-juvenis, integrando-os nos hospitais gerais centrais e distritais (Portaria n. 750/92, de 1 de agosto). Desde esta altura quase todos os hospitais têm departamentos psiquiátricos e serviço de urgência psiquiátrica. (ALVES, 2011, p. 51).

Uma tentativa de descentralização, pulverizando a questão da saúde mental, agregando-a a outros serviços de saúde, parece-nos uma estratégia pertinente para extinguir os conteúdos segregatórios referenciados aos serviços especializados nesta área. Saúde mental faz parte da saúde. Isto é explicitado também neste decreto-lei. Mas houve resistência, que Alves remete à psiquiatria:

Significativo da resistência que a psiquiatria portuguesa sempre conseguiu oferecer, com sucesso, à definição legal da reforma psiquiátrica no sentido da desinstitucionalização, é o facto de esta decisão governamental ter sido fortemente contestada pela profissão psiquiátrica e suas associações com o argumento de que a psiquiatria nos hospitais gerais significava um retrocesso na medida em que reforçava a institucionalização. A classe que contestou esta integração aceitou, no entanto, que os grandes hospitais psiquiátricos continuassem a existir. (ALVES, 2011, p. 51).

Considerando que a centralização do poder médico-psiquiátrico tinha estabilização suficiente para instituir certas práticas, entende-se que o modelo biomédico servia de base às decisões, e as opiniões nele fundadas eram respeitadas. Os sons das outras vozes não estavam sendo ouvidos. Não que eles não existissem, mas não ecoavam. O peso dos hospitais, o isolamento das estruturas, o sofrimento dos usuários e também dos profissionais se coadunavam com as clausuras de suas vozes. $\mathrm{O}$ modelo manicomial impõe muros que se perpetuam nos modos de funcionamento. 
Há que se ouvir todas as vozes, para que a harmonia possa ser organizada a contento. Apostar ou não nos hospitais psiquiátricos como solução dos problemas é somente parte da discussão que deve ser debatida e compartilhada por todos os segmentos envolvidos em saúde e cuidados.

Apesar das várias tentativas políticas, a adopção da filosofia da psiquiatria centrada na comunidade falhou, malgrado recomendações internacionais e a pressão de alguns grupos minoritários dentro e fora do sistema. [...] Estas contradições ou 'descoincidências' que permeiam a Política de Saúde Mental portuguesa entre o que está legalmente definido e o que realmente vigora e orienta as práticas traduz a tolerância aos interesses corporativos que tem pautado a actuação do Estado (ALVES, 2011, p. 51).

Esta citação traduz um inconformismo, mas ao mesmo tempo, ela trata de tolerância a interesses corporativos. Quais os outros corporativismos produzidos que não estão visíveis? Quais as outras forças que podem ser acessadas e que se encontram enfraquecidas? São citados grupos minoritários, e a pesquisa revelou as insatisfações de alguns profissionais. Mas a quem cabe a virada, a resistência, a mobilização? Cabe ao Estado? Aos psiquiatras? Estes estão com suas conexões estabilizadas e visíveis e detêm o poder de decisões. As leis são imprescindíveis para as mudanças, mas e o contágio? E as outras conexões políticas, as micropolíticas, as vozes insatisfeitas?

Os usuários defendem a continuação dos hospitais psiquiátricos? Os familiares os defendem? E os profissionais não-médicos, o que têm a dizer?

No Brasil, as iniciativas de desconstrução do modelo manicomial começaram pelos profissionais, residentes e outros que discordaram dos modos de funcionamento dos hospícios e começaram uma discussão política num movimento que deflagrou a Reforma Psiquiátrica no Brasil (AMARANTE, 1995). Não basta assumir um discurso como o veredito sobre os tratamentos, cabe refazê-los e debatê-los ao som das vozes, conflituais ou não, e mesmo assim, propondo o diálogo.

Nosso intuito aqui é promover a discussão sobre como as noções, práticas, implementação ou não de serviços e estabilização de conexões devem constituir um processo de contágio. E isto pode interessar a todos os envolvidos. Rizomaticamente, pode-se fazer desmontar grandes estruturas tomadas como verdades instituídas e estabelecidas. Os muros dos hospícios podem se propagar ou dissolverem-se a partir das conexões de cada actante destas redes. As vozes podem soar em ondas e promulgar a liberdade. E esta será para todos, os que concordam, os que discordam, os que querem manter e os que querem desconstruir os muros manicomiais. Não basta culpabilizar o psiquiatra, o familiar, o Estado, o utente, ou o quadro nosológico. Trata-se de desestabilizar o existente para poder abrir espaços novos de possibilidades. Provocando as linhas de fuga, os desvios, os desloca- 
mentos, com as participações de todos os envolvidos. Assim, as redes se burilam mais fortemente e as conexões se modificam, criando outras possibilidades, outros devires, outros serviços, outros modos de atuar e pensar em saúde mental.

É do encontro entre as forças pró e contra os diferentes modos de funcionamento que poderão surgir outros modos de olhar e atuar em saúde mental. Se é necessário polir as lentes, parodiando Espinosa, pensamos que é necessário também fazer as lentes e usá-las. Não há fórmula, não há modelo, não há modos de pensar diferenciados que prescindam do embate, do contágio de ideais, de ideias e de fazeres, de saberes e de não-saberes. Talvez eleger os vilões seja mais fácil do que enfrentá-los. Mas isto também faz parte da luta e do engajamento político.

A resistência da classe médica à integração da saúde mental nos cuidados de saúde primários prende-se, em grande parte, com a relação entre serviços públicos e privados que tem sido apelidada de 'promíscua', dada a não regulação da possibilidade de os profissionais poderem trabalhar simultaneamente em ambos, exercendo desta forma interesses que podem também ser conflituais e não apenas complementares. A divisão do tipo de trabalho entre serviços públicos e privados ilustra este fenómeno. (ALVES, 2011, p. 52).

Todas as tentativas de mudança até o presente não foram em vão, e não serão necessariamente enfraquecidas. As leis são materialidades importantes e, somadas às iniciativas e a outros interesses, podem ajudar às conquistas no processo de desinstitucionalização.

Familiares entraram em cena, também tentam e querem o melhor para os seus parentes, eles contribuem para o processo e são parte importante deste.

"Os médicos obstaculizam as atividades familiares nos lares, utilizam consultórios e gabinetes. A lei da intervenção de internamento compulsivo também recomenda medidas de atividades ocupacionais, residências terapêuticas etc. Lei de Saúde Mental. Os hospitais-dia são um proforma: é um fingimento. Finge que se faz qualquer coisa. Está integrado no hospital psiquiátrico". (Carlos Araújo, familiar, entrevista em 15/06/2011).

Evidencia-se a responsabilização do Governo na criação de serviços comunitários. O governo foi o agenciador da criação de leis que estabeleciam a criação destes serviços, mas que forças podem pressioná-lo à implementação? Conexões financeiras? Pressões de outros segmentos da sociedade civil organizada? Profissionais reivindicando? Familiares se associando? O que mais pode ser inventado para quebrar a lógica do despotismo das soluções prontas e referenciadas a um agente isolado? Onde estão as brechas para dissolver estes constructos? Onde estão os focos de mobilizações? Eles existem. 
"Os atendimentos em hospitais gerais funcionam mais para dentro. O Plano Nacional prevê não só a descentralização, mas fazer um atendimento comunitário. Os cuidados comunitários não precisam ser liderados pelos médicos. Os médicos teriam que ir para as comunidades, mas isto não aconteceu. Eles deveriam estar a defender o atendimento comunitário". (Profa. Dra. Luisa Brito, enfermeira, entrevista em 27/06/2011).

A citação acima é um efeito que no Brasil está repercutindo. Isto é uma voz que a muitas outras deve se somar para provocar transformações que ratifiquem todas essas leis que esclarecem as diretrizes. As pressões é que mobilizam o conflito de interesses, as conexões com novos actantes, as traduções, as recalcitrâncias, isto tudo é necessário para mobilizar, burilar e provocar desvios. Estes nem sempre são previsíveis, mas isto faz parte do processo. Se os serviços comunitários já foram apontados como uma diretriz, os diretamente interessados na sua criação e desenvolvimento deverão acionar as forças que puderem ser mobilizadas nesse sentido.

Em Portugal, cabe destacar a década de 1990 como um período em que se agenciaram várias iniciativas no sentido de integração da saúde mental com outros segmentos e também de criação de novos serviços. Esta década demonstra uma organização explicitada dos horizontes a serem conquistados no campo da saúde mental. Em 1994, houve a nomeação pelo Director-Geral da Saúde de uma Comissão para o Estudo da Saúde Mental (CESM). Esta formou grupos de trabalhos engajados em formatar as diretrizes da saúde mental para o país. Buscava-se uma congruência do "sistema existente com o novo quadro dos serviços de saúde baseados na regionalização e na criação de unidades de saúde" (ALVES, 2011, p. 52-53). Destes grupos surgiu um relatório (1995), intitulado "Princípios de Organização dos Serviços de Saúde Mental - Saúde Mental: Proposta de Mudança" (ALVES, 2011, p. 53). Os princípios organizacionais que deverão estar contidos em todos os serviços de saúde mental, segundo Alves (2011, p. 53) são:

- Sectorização, que garanta a responsabilização pelos cuidados prestados em cada unidade geodemográfica;

- Continuidade de cuidados;

- Desenvolvimento de cuidados a nível da comunidade;

- Diversificação e coordenação comum dos dispositivos que integram a rede de serviços de cada sector;

- Articulação funcional dos serviços especializados de saúde mental com os outros serviços de saúde;

- Reestruturação da hospitalização psiquiátrica, no sentido da hospitalização dos doentes agudos nos hospitais gerais e na criação de dispositivos facilitadores da reabilitação e desinstitucionalização dos doentes de evolução prolongada e 
- Envolvimento de pacientes, famílias e outras entidades da comunidade nos cuidados de saúde mental.

Este é o desenho da nova política de saúde mental em Portugal. Todas as tentativas que se seguiram balizaram-se nestas proposições. Havia a disposição para aproximar e integrar a saúde mental nos serviços de saúde geral. A preocupação dos atendimentos serem distribuídos pelo país ajudou a agregar os interesses para que descentralizassem os serviços, levando cuidados a toda a população. Alves (2011, p. 53) enumera as propostas do modelo organizacional:

- Criação de dispositivos de saúde mental nas unidades de saúde para uma área geodemográfica de 250.000 habitantes.

- Criação de unidades de saúde mental infanto-juvenis nas unidades de saúde respeitando o mesmo rácio.

- Criação de serviços a nível regional capazes de apoiar os serviços locais implantados em cada unidade de saúde, e ainda os Centros Regionais de Alcoologia (a nível regional estes serviços deverão incluir também serviços de psiquiatria forense, de psicogeriatria e de toxicodependência).

O esforço de organização destes grupos de trabalho incidiu sobre os princípios da Psiquiatria de Setor, organizando as diretrizes, o que incrementou a reformulação das argumentações e permitiu que fossem atualizadas as problemáticas. Muitas dessas premissas estão presentes nos programas de saúde mental brasileiros.

Ao final da década de 1990, o governo português promulgou uma nova Lei de Saúde Mental. Publicada em 24 de julho de 1998 (Lei n. 36/98), ela propõe a descentralização dos hospitais em serviços na comunidade, sendo estes "a base do sistema nacional de saúde mental [...]. A verdade é que não foram criados serviços locais de saúde mental [...] sendo os doentes e suas famílias sujeitos a um processo errático de desinstitucionalização". (HESPANHA, 2010, p. 139).

As críticas estão presentes, elas falam de uma não apropriação e/ou responsabilização governamental pelos utentes, mas ao mesmo tempo, escrevem sobre as leis promulgadas. O que mais poderia fazer o governo, sem muita pressão popular, além de criar leis? A criação de serviços nos parece uma resposta razoável a esta pergunta, mas não a compreendemos como suficiente. Os serviços a serem criados e a insistência aos ideais libertadores das práticas manicomiais devem ser uma conquista dos diretamente interessados. Acreditamos que os direitos só serão efetivamente assegurados e viabilizados quando houver esta pressão política organizada e fortalecida.

Com relação aos utentes com histórico de muitos anos de internação em hospitais psiquiátricos, o governo português propôs também em 1998:

A Lei de Saúde Mental (de 1998) enumera os direitos fundamentais dos doentes e determina que a prestação de cuidados seja promovida prioritariamente ao nível da comunidade [...] São valorizadas unidades de reabilitação, 
estruturas residenciais para doentes de evolução prolongada e estruturas para formação e reinserção profissional. (HESPANHA et al., 2012, p. 13-14)

Interessante observar que o processo de desinstitucionalização requer um investimento em dispositivos de retomada de hábitos diários dos utentes que ficam muito tempo internados. Perdem-se os referenciais que antes abarcavam autonomia e segurança. A institucionalização dos hábitos imobiliza o utente para a vida fora do hospital. Muitas vezes ele fica tão alienado que precisa reaprender a lidar com dinheiro, andar pelas ruas, entrar e sair dos ambientes. Ele se desacostuma a viver fora dos muros hospitalares e as propostas antimanicomiais não podem prescindir deste cuidado. A volta ao lar e/ou outras comunidades deve contar com um trabalho das equipes de cuidado. O sorriso na face, a alegria de estar de novo entre os outros, como todos. Andar sozinho, pegar autocarro (ônibus), deslocar-se no território, descobrir lugares e interagir com pessoas. Para qualquer pessoa não asilada, estas atividades da vida diária podem parecer banais, mas para quem viveu anos de segregação, isolamento e torturas manicomiais, assemelha-se a voltar a viver.

O governo português investiu em proposta de geração de renda e emprego para os utentes,

também se criaram programas no âmbito do mercado social de emprego, que se constituem como a principal resposta do Estado neste âmbito. A Portaria n. 348-A, de 18 de Junho de 1998, vem criar a medida de Empresas de Inserção dirigidas a pessoas com doença mental (ALVES, 2011, p. 54).

Esforços semelhantes foram desenvolvidos no Brasil. Viabilizar a obtenção de emprego é um passo largo no resgate de liberdade para o institucionalizado e também previne a institucionalização dos que utilizam os serviços como iniciantes. Se isto não acontecer, se a única opção de tratamento for o hospital psiquiátrico, não há outra saída além da institucionalização. Isto ocorreu no Brasil por décadas, mas a Reforma Psiquiátrica veio tentar modificar esta lógica excludente. Em Portugal, também foram criados outros modos de inserir socialmente os utentes já com trajetória de institucionalização, as chamadas "famílias de acolhimento". Esta peculiaridade traz uma perspectiva de convivência em comunidades compartilhando espaços e dinâmicas familiares.

Trata-se de um recurso temporário ou de longo prazo. As suas potencialidades são sobretudo económicas (baixo custo comparativamente com outras soluções), para além da característica de flexibilidade que lhes permite dinamizar sistemas de apoio natural, integrados na comunidade. (ALVES, 2011, p. 55).

Além destas iniciativas e investimentos governamentais, Alves cita a presença de associações de utentes. 
A sociedade civil secundária tem corporificado algumas responsabilidades sociais, nomeadamente pela organização de equipamentos sociais. Mas as associações que se foram desenvolvendo a nível da doença mental são relativamente recentes e a sua acção, se bem que importante, não responde de uma forma sistemática às necessidades. (ALVES, 2011, p. 55).

Ela complementa que os serviços que as associações engendram vêm tamponar o que o governo não comporta, mas insere que as atividades das associações não abarcam todo o país. Ainda acrescenta: "a capacidade reivindicativa e de pressão desta categoria da população (doentes mentais) é praticamente inexistente, porque silenciada, através do modelo médico de naturalização e individualização do fenómeno, que impede a sua percepção enquanto problema social" (ALVES, 2011, p. 55). A quem cabe a transformação da lógica excludente manicomial? Ao governo, a iniciativa privada, ao usuário, ao familiar ou aos profissionais? Estar insatisfeito é uma possibilidade. Reclamar, apontar erros, identificar falhas e eleger culpados é uma posição. Ao invés de olharmos estas organizações como insuficientes, preferimos retê-las como importantes conexões que podem agenciar interesses de quem utiliza os serviços. Compreendemos que associações de usuários, profissionais e amigos de serviços de saúde mental podem se transformar em agentes mobilizadores de muitas forças, agregar interesses a quem interessa e de quem se interessa. A fala do usuário e do familiar não vai ser substituída por decreto-lei nenhum. Como nos disse um dos entrevistados: "O relato do familiar é insubstituível" (José Morgado, entrevista em 15/06/2011). É importante ouvir esta fala. E mesmo que as associações ainda não abarquem todo o território, temos que congratular-nos porque elas conquistaram uma existência e produzem discussões pertinentes. Identificamos associações de utentes e afins como um importante dispositivo de mobilização política, em todos os seus termos associados. A reivindicação surge quando as insatisfações encontram eco e, para isto, é necessário amplificar esta voz. O profissional de saúde mental, o pesquisador, o familiar podem ajudar a ampliar esta voz, mas a voz do utente não pode ser substituída por qualquer outra. É dele.

Este aspecto é bem ilustrado por uma entrevista feita com um familiar participante da Associação VIME (Viver Melhor) de Portugal, que tem passado por dificuldades desde início de 2008:

"Percebi que os familiares não são bem informados. Resolvemos ter associação para trocar experiências. Teve palestras de informação sobre temáticas várias, sexualidade, medicamento, segurança social, com profissionais qualificados. Programas em rádios, Ministério da Saúde, do Trabalho, com comissários da polícia, com a delegação de saúde. Pedimos policiais não fardados em carros não identificados. A Associação conquistou isto. Isto era menos traumático. Voluntários ajudaram: médicos, psicólogas, psiquiatras, familiares. Durou aproximadamente 9 anos. [...] 
Planejamos uma casa para atividades de vida diária, quase conseguimos a verba. A Associação está enfraquecida. Esta associação construiu uma casa, compraram e reformaram para ser um lar para saúde mental. Papel fundamental era contato com familiares, informação. Tem estatuto e aprovaram na Seguridade Social. Há um centro de saúde de cuidados primários, ligação com as pessoas, com as famílias. Saúde básica, cuidados básicos de saúde. A Associação teve apoio de escola superior de enfermagem. Estagiárias para levantamento de pessoas com problemas de saúde mental nas famílias. Avaliação clínica social das famílias. Disponibilizaram uma sala para a VIME. [...] O projeto não continuou. Acabou este projeto no ano de 2003/2004 [...] Tinham 160/170 participantes na associação. Seguiam os objetivos com qualidade. E isto cativou vários profissionais". (Carlos Araújo, ${ }^{10}$ entrevista em 15/06/ 2011).

Pensamos que existem muitas dificuldades para lidar com os problemas em políticas de saúde mental em Portugal tanto quanto acontecem no Brasil, mas destacamos este relato do familiar para ratificar a posição de que existem tentativas, buscas, investimentos direcionados às soluções das dificuldades. Identificamos que as Associações devam ser potencializadas, articuladas, fortalecidas por todos os interessados em transformar as realidades até então produzidas, inferindo outros modos de ver, atuar e somar aos enfraquecidos na luta-para que se consiga reverter tanto o sentimento de que não se pode fazer nada, quanto a percepção de que nada está sendo feito para melhorar. Ainda existe um discurso recorrente em saúde mental, o de que não se faz nada para mudar. Há que se buscar as linhas de fuga, os rastros das conexões desviantes, os efeitos, mesmo que aparentemente pequenos, das redes que agregam as tentativas de melhorar. Esta é a luta. E ela está em curso.

Alves associa crítica às decisões governamentais com o engajamento das famílias:

O Estado usa as famílias como recurso da implementação da psiquiatria comunitária desinstitucionalizante, na qualidade de 'substitutas' das estruturas extra-hospitalares (não existentes), e não como parceiros da estratégia terapêutica e de reabilitação. Não há diálogo, nem troca, mas transferência de tutela. $\mathrm{O}$ doente deixa de estar sob a responsabilidade do hospital e passa para a família. (ALVES, 2011, p. 55).

A quem cabe mudar esta situação? Dizer que as associações estão enfraquecidas e/ou culpabilizar o Estado nos parece uma atitude paralisante. A nós interessa problematizar: quais são os deslocamentos possíveis a essa lógica? Quais são os desvios? Onde estão as linhas de fuga? Quais conexões estão sendo agenciadas localmente nestas relações? E os usuários/utentes, o que pensam sobre isto? 
Uma profissional entrevistada que atua no campo da saúde mental identificou uma implementação bem sucedida, segundo ela, dos pressupostos da política de saúde mental em Portugal, uma experiência na localidade de Viseu, na região Centro de Portugal:

"O Plano Nacional de Saúde Mental prevê o que tem em Viseu, uma equipe multidisciplinar responsável por um setor geográfico, com serviço de internamento, ambulatório, apoio domiciliário e programas de apoio a emprego. Em paralelo a rede nacional de cuidados continuados e integrados em saúde mental que saiu em 2010. A lei, o despacho que prevê vários tipos de estruturas de apoios domiciliares, residências de vários tipos e também equipe de apoio domiciliares e centros de apoios ocupacionais com apoio ao emprego. Para os doentes melhores. Não é pra ficar internado. Em Viseu existem instituições privadas com subvenção pública que se articulam com o serviço de psiquiatria e dão apoio aos utentes. Procure a ASSOL- Associação de Solidariedade Social de Lafões, fica perto de Viseu. Emprego protegidoempresa ou posto que pressupõe supervisão continuada". (Luisa Brito, ${ }^{11}$ entrevista em 27/06/2011, Coimbra).

A fala da entrevistada já aponta uma dissonância em relação à posição de que as proposições descentralizadora e comunitária não estariam ocorrendo localmente no território português.

As possibilidades de mobilizações estão presentes. Apontamos as associações como redes importantes. Estas e outras iniciativas podem promover as vozes dos utentes, para ouvir deles as soluções, apontar caminhos, vislumbrar saídas dos muros manicomiais. Alves ratifica seu ponto de vista com a seguinte afirmação: "Portugal desinstitucionalizou os seus doentes mentais sem criar estruturas comunitárias, para o que se apoia na solidariedade da família. Ou seja, Portugal 'trans-institucionalizou' os seus doentes mentais na família" (ALVES, 2011, p. 56). A questão que colocamos é: o que os utentes prefeririam, estar em serviços comunitários ou em ambientes familiares? Esta foi uma decisão do governo somente? Que actantes se agregaram para compor esta estabilização? Para esta assertiva ser coerente, é necessário que muitos actantes tenham se conectado. As famílias estão satisfeitas? Os usuários corroboram? A autora citada reivindica a criação de serviços comunitários, com o que concordamos. Contudo, entendemos que as materializações são produzidas conectando-se interesses, ações, humanos e não-humanos. Resta saber quais são os actantes conectados nestas redes para a produção destes efeitos. E seguem-se as leis...

Já em pleno século XXI um novo plano de ação foi criado, propondo uma reestruturação dos Serviços de Saúde Mental. Este plano reconfigura a constituição dos hospitais. Um plano de mobilização institucional, no qual se redistribuíram as unidades e alguns pacientes foram removidos e transportados. O Plano de Acção para 2007-2016, assim chamado, foi aprovado em 2007 e ainda está em execução. 
Este Plano parte de uma estrutura de serviços públicos constituída por seis Hospitais Psiquiátricos (dois em Lisboa, três em Coimbra e um no Porto), por três Departamentos de Psiquiatria e Saúde Mental da Infância e Adolescência (nestas três cidades) e trinta Serviços Locais de Saúde Mental, quatro deles sem internamento próprio, internados em Hospitais Gerais e disseminados por todo o país [...] e de serviços privados constituídos por três instituições. (HESPANHA, 2010, p. 140).

Inferimos que uma mudança substancial nos modos de lidar com os utentes de serviços de saúde mental não caberia somente nos muros institucionais e instituídos da loucura. Mas entendemos que certas mudanças podem ser conectadas a instâncias de poder instituídos e a processos instituintes, ligados a mobilizações ou intervenções de ativistas e/ou de profissionais. Isto requer tanto procedimentos governamentais quanto mobilizações político-ativistas.

\title{
Sobre Psiquiatria de Setor e Reforma Psiquiátrica - trechos das ENTREVISTAS
}

Os entrevistados, de modo recorrente, falaram dos serviços implementados e também apontaram críticas.

\begin{abstract}
"Antipsiquiatria nunca entrou em Portugal. O que entrou em Portugal era psiquiatria de setor. Era feito em hospício, isto era um problema. Fazia comunidade mas não sítio. Há um médico psiquiatra que mora em Setubal, foi ele que trouxe a psiquiatria de setor para Portugal. Braulio de Almeida. A única psiquiatria que entrou em Portugal foi a psiquiatria de setor". (Rui Mota Cardoso, ${ }^{12}$ entrevista em 28/06/2011, Porto).
\end{abstract}

Mota Cardoso aponta para estas duas correntes que se desenvolveram na Europa, mas localiza a abordagem seguida em Portugal. Quais os actantes envolvidos para as produções da psiquiatria de setor em Portugal? O poder continuou centralizado no saber médico-psiquiátrico? A antipsiquiatria e a Reforma Psiquiátrica questionam este saber. Nestes processos, outros profissionais entram no cenário e a descentralização vai além de unidades de serviços de saúde mental. Ela invade também as equipes profissionais, desestabilizando o lugar do saber-poder psiquiátrico. As proposições de equipes interdisciplinares, multiprofissionais e transdisciplinares abrem as articulações de saberes para enfoques diferenciados. O saber e não-saber são compartilhados entre todos, com a participação do usuário do serviço como agente importante e imprescindível no próprio tratamento. Em Portugal, através de informações advindas da bibliografia consultada unida aos relatos das entrevistas, pode-se concluir que as deliberações ficaram concentradas no governo, com as materialidades das leis recorrentes e no poder dos médicos-psiquiatras que geriram as decisões nos serviços. Luisa Brito contrapõe: 
"A psiquiatria de setor de abordagem francesa foi coisa do passado [...]. Há resquício disto no Sobral Cid, cada pavilhão de homens e de mulheres teria uma certa área geográfica. Mas atualmente está o hospital psiquiátrico e mais nada. E serviços de psiquiatria nos hospitais gerais. Em 2007 saiu um Plano Nacional de Saúde Mental que preconiza que se encerre os hospitais psiquiátricos e que toda a psiquiatria se faça em saúde mental comunitária. Que haja equipes de saúde mental comunitária. Que em hospital geral haja um departamento de psiquiatria. Eles só trabalham dentro de paredes". (Luisa Brito, entrevista em 27/06/2011).

Há uma crítica pertinente a modos de tratamentos que se encerrem no modelo clínico tradicional, tipo consultório-paciente-médico. Se a proposta do plano de ação português é tratar na comunidade, este modo de atendimento não se aplicaria de modo rígido.

A Reforma Psiquiátrica foi adotada no Brasil, principalmente a partir do final da década de 1970. Sua proposta é acabar com os manicômios/hospitais psiquiátricos e, para isto, criar serviços substitutivos. Seu principal expoente é o italiano Franco Basaglia. José Morgado comenta:

"Basaglia foi mais visto como arauto de uma psiquiatria muito politizada, e os seus trabalhos pouco divulgados. Aqui não tem CAPS. Mais parecidos com os CAPS, são os Hospitais de Dia, que surgiram nos Hospitais Gerais e nos Hospitais Psiquiátricos, e os Centros de Saúde Mental, depois integrados nos Hospitais gerais como departamentos. [...] Os centros de saúde mental foram integrados nos hospitais gerais. Os hospitais-dia surgiram nestas unidades [...] Há retórica no discurso da desinstitucionalização, estes processos são complexos. Antes havia a institucionalização. Deve se perceber em concreto a institucionalização e a desinstitucionalização. Para fugir às retóricas ideológicas. [...] Pessoas foram colocadas nas ruas depois de anos de internação. Sem qualquer alternativa. Isto é violência maior". (José Morgado, entrevista em 15/06/2011).

Interessante observar que a proposta dos CAPS no Brasil é a de que eles sejam criados longe de hospitais psiquiátricos, o que não aconteceu em Portugal, onde os hospitais-dia ${ }^{13}$ foram deliberadamente criados em vinculação de proximidade. No Brasil, propunha-se a distância do hospital para não replicar as práticas manicomiais.

Foi justamente o cunho político da vertente basagliana que alavancou a adesão dos trabalhadores em saúde mental, incentivou as lutas antimanicomiais e contribuiu para o efeito rizomático. Mas entra um contraponto: a mesma crítica que vimos formulada a propósito de Portugal quanto às pessoas ficarem desassistidas acontece no Brasil. A crise financeira vivida atualmente pela Europa há 
muito mais tempo acomete os brasileiros. Os profissionais da saúde mental do Brasil, os governantes, os familiares e os próprios usuários conviveram e ainda convivem com situações deficitárias quanto ao poder aquisitivo, as seguridades e os direitos mínimos à saúde, moradia, segurança, educação. Estão em curso no Brasil mudanças sociais significativas orientadas para redução das desigualdades sociais e promoção dos direitos à cidadania, incluindo o direito à saúde. A construção do Sistema Único de Saúde e a criação de redes e movimentos ligados à saúde são contribuições fundamentais para essas mudanças.

Os actantes envolvidos nestas mudanças pertencem às redes brasileiras de saúde, e todos temos que lidar com isto em nossas socialidades-materialidades. Muitos usuários abandonados, população moradora das ruas em risco social aparecem como problemas sérios, complexos. Necessitariam de muito mais do que medicamentos ou equipes interdisciplinares para sua sobrevivência. Institucionalizar seria uma violência e, infelizmente, existem outras.

No Brasil, Franco Basaglia foi sinônimo de incentivo e mobilização nos ideais da Reforma, em Portugal isto não aconteceu.

\begin{abstract}
"A psiquiatria basagliana não existe mais. Como movimento não existe mais. Aconteceu na Itália que, com tanto entusiasmo, no primeiro momento eles fecharam os asilos, e agora se criou má vontade, porque eles se tornaram pedintes nas ruas. [...] $\mathrm{Na}$ década de 1960 éramos ingênuos. O Basaglia tinha o entusiasmo. Toda a vivência é social. O modelo era que não havia doença. Não podemos abandonar a ideia de que o doente é um doente". (Rui Mota, entrevista em 28/06/2011).
\end{abstract}

Os dois psiquiatras entrevistados, um com atuação em Coimbra e o outro no Porto, foram categóricos quanto às críticas ao modelo basagliano de Reforma Psiquiátrica. Estas críticas também existem no Brasil, mas aqui se agenciaram outros actantes, e a politização da saúde mental, ao invés de promover uma resistência, foi o que mais proporcionou a adesão à Reforma. Saboreamos o entusiasmo de trabalhar para acabar com os hospitais psiquiátricos, atentos e engajados para que outros serviços fossem criados para evitar o abandono dos usuários nas ruas. Estou presente há vinte anos neste cenário, enquanto profissional de saúde mental, somados os últimos oito anos em vida acadêmica como pesquisadora. As conferências de saúde mental, as reuniões da luta antimanicomial, as comemorações do Dia Nacional da Luta antimanicomial. As aprovações das leis, os debates em equipes interdisciplinares, nas discussões de cada caso, o fato de negociarmos o projeto terapêutico com o usuário, a participação em assembleias deliberativas, tudo isso é um mote de serviço profissional. Crenças, lutas, interesses, investimentos financeiros, temporais, dedicação de tantos por tantas pessoas valeram-se dos ideais da Reforma Psiquiátrica. Mas isto não quer dizer que ela seja a única nem a melhor abordagem no trato dos usuários de serviços de saúde mental. Há os que discordam, criticam, atacam, mas as estabilizações nos serviços públicos ainda apontam para esta vertente. Esta rede, de certo modo, produziu conexões fortes, agregou muitos actantes e se mantém estabilizada com ascensão desde a 
década de 1990. Muitos debates, enfrentamentos, posicionamentos, mobilizações micropolíticas, organizações de profissionais e, além disso tudo, e muito mais importante, incluir o utente nesta discussão. Ele é o mais interessado, já que o tratamento deve ser direcionado para ele. Percebemos que, para convencer um médico a atender no modo comunitário, muita coisa deve ser traduzida na rede além de leis. Lidar com as recalcitrâncias é um desafio, mas é necessário para as mudanças. As melodias contemporâneas contemplam as dissonâncias.

A discussão, o embate, a luta deve acontecer para que as decisões não venham prontas, já homogêneas e colocadas. Há que se burilar os constructos e mobilizar as redes, para que mudanças ocorram. Ancoradas nos discursos de quem utiliza os serviços, de quem vivencia as dificuldades e identifica os pontos de fragilidade.

\section{CONSIDERAÇões FINAIS: EFEITOS DESTAS CONEXõeS}

Não é possível identificar todos os efeitos das conexões entre leis de saúde mental, as relações destas nos serviços, e as práticas e experiências de profissionais, familiares e utentes de Portugal. Mas existem críticas, insatisfações e também credibilidades. O saber médico se institui à medida que outros saberes $\mathrm{o}$ reconhecem e o ratificam. É importante que existam as críticas e que elas possam se transformar em catalisadores e impulsionadoras de outras tentativas de mudanças. As leis já estão promulgadas, resta serem implementadas. Mas para isto muita mobilização será necessária. Muitos actantes engendrados, interesses em discussão, luta com seus ganhos e perdas consequentes. Atendimentos dentro ou fora do consultório implicam em mobilidades maiores, das ideias, ideais, informações, mas principalmente contágio destes. Acreditamos que coletivamente tudo é possível. Isoladamente, pouco se consegue. É possível que isto possa estar acontecendo com os médicos. Deve pesar a sobrecarga da responsabilidade da centralização do poder sobre o tratamento do utente. A partir da bibliografia consultada e dos relatos dos entrevistados, é plausível sugerir que a Psiquiatria de Setor ainda não atingiu integralmente sua proposição de atendimento comunitário. Os atendimentos mantêm-se prioritariamente num procedimento biomédico. Uma outra questão, embora não destacada, torna-se presente: a crise financeira que atravessa o país. Seus efeitos sobre a saúde mental não foram explorados neste artigo.

Os efeitos das conexões observadas nos impele a apostar nas possibilidades de trocas, debates, discussões, associações entre utentes, familiares, profissionais e outros afins às causas da saúde mental, para integrar os interesses em objetivos comuns.

Brasil e Portugal produziram modos diferenciados de elencar os interesses e forças comuns para buscar melhoria nos atendimentos, serviços e unidades de saúde mental.

Pensamos que os efeitos produzidos em cada abordagem adotada sejam diferentes e derivem das conexões que se agenciarem nas redes. 
Portugal continua sua luta, que começou antes da dos brasileiros. Mas o mais importante é que em ambos os países se estão viabilizando recursos, leis, serviços, embates, para melhorar a qualidade do atendimento aos utentes/usuários.

\section{Notas}

${ }^{1}$ Em Portugal, os usuários de serviços de saúde mental são chamados de utentes.

${ }^{2}$ Moraes (1998, p. 51) sublinha que numa entrevista concedida em 1993, Latour prefere utilizar a palavra actantes no lugar de atores para despir tal noção de seu cunho personalístico, subjetivista. Actantes são coisas, pessoas, instituições que têm agência, isto é, produzem efeitos no mundo e sobre ele.

${ }^{3}$ Em Portugal, os usuários de serviços de saúde mental são chamados de utentes.

${ }^{4}$ Primeira edição em 1961.

${ }^{5}$ Primeira edição em 1961.

${ }^{6}$ Primeira edição em 1963.

${ }^{7}$ Primeira edição em 1968.

${ }^{8}$ Psiquiatra já aposentado pelo Hospital Sobral Cid, em Coimbra.

${ }^{9}$ IAP- Instituto de Assistência Psiquiátrica (1976). Bases Gerais da Integração dos Serviços de Saúde Mental no Serviço Nacional de Saúde. Porto: Edição do Instituto de Assistência Psiquiátrica da Zona Norte.

${ }^{10}$ Familiar de utente dos serviços de saúde mental em Portugal que exerceu a função de presidente da VIME. Tivemos autorização expressa para constar aqui seu nome original.

${ }^{11}$ Enfermeira, mestre em psiquiatria e saúde mental no Porto, mestrado transdisciplinar e doutora em Enfermagem pela Universidade de Lisboa.

${ }^{12}$ Médico pela Universidade do Porto, tendo-se doutorado na especialidade de Psiquiatria. Professor catedrático da Faculdade de Medicina, foi diretor do Serviço de Psicologia Médica da mesma Faculdade.

${ }^{13}$ Em Portugal, o hospital-dia é designado hospital de dia.

\section{REFERÊNCIAS}

ALVES, F. A doença mental nem sempre é doença: racionalidades leigas sobre saúde e doença mental - um estudo no norte de Portugal. Porto: Afrontamento, 2011.

AMARANTE, P. (Org.) Loucos pela vida: a trajetória da reforma psiquiátrica no Brasil. Rio de Janeiro: SDE/ENSP, 1995.

BASAGLIA, F. A instituição negada. $3^{\text {a }}$ Ed. São Paulo: Graal Editora, 2001.

FOUCAULT, M. História da loucura na idade clássica. $8^{a}$ Ed. São Paulo: Perspectiva, 2005.

FOUCAULT, M. O Nascimento da Clínica. $6^{\text {a }}$ Ed. Rio de Janeiro: Editora Forense Universitária, 2004.

GOFFMAN, E. Manicômios, Prisões e Conventos. Trad. Dante Moreira Leite. $7^{\mathrm{a}}$ edição. São Paulo: Editora Perspectiva, 2001.

HESPANHA, P. A reforma psiquiátrica em Portugal: desafios e impasses. In: FONTES, B. A. S. M.; FONTE, E. M. M. (Org.). Desinstitucionalização, Redes 
sociais e Saúde Mental: análise de experiências da reforma psiquiátrica em Angola, Brasil e Portugal. Recife: UFPE, 2010. p. 137-162.

HESPANHA, P. et al. Doença Mental, Instituições e Famílias: os desafios da desinstitucionalização em Portugal. Coimbra: Almedina-CES, 2012.

MORAES, M. Por uma estética da cognição: a propósito da cognição em Latour e Stengers. Informare, Rio de Janeiro, v. 4, n. 1, p. 49-56, 1998.

PORTUGAL. Constituição (1976). VII revisão constitucional [2005]. Disponível em: <http://www.parlamento.pt/Legislacao/Paginas/ ConstituicaoRepublicaPortuguesa.aspx>. Acesso em: 20 maio 2013.

PORTUGAL. Assembleia da República. Lei no 36/98 de 24 de julho. Lei de Saúde Mental. 1998. Disponível em: <http://dre.pt/pdf1s/1998/07/169A00/35443550. pdf>. Acesso em: 20 abr. 2013.

PORTUGAL. Portal da Saúde. História do Serviço Nacional de Saúde. 2010. Disponível em: <http:/www.portaldasaude.pt/portal/conteudos/ $\mathrm{a}+\mathrm{saude}+\mathrm{em}+$ portugal/servico+nacional $+\mathrm{de}+\mathrm{saude} / \mathrm{historia}+\mathrm{do}+\mathrm{sns} /$ historiadosns.htm>. Acesso em: 17 abr 2013.

ROUDINESCO, E. [et. al.]. Foucault: leituras da história da loucura; tradução Maria Inês Duque Estrada- Rio de Janeiro, Relume-dumará, 1994.

SIQUEIRA-SILVA, R. Grupos musicais em Saúde Mental: conexões entre estética musical e práticas musicoterápicas. 2012. Tese (Doutorado em Psicologia-Estudos da Subjetividade)-Instituto de Ciências Humanas e Filosofia - Universidade Federal Fluminense, Niterói, 2012.

VIANA, V. C. Saúde mental, qualidade de vida e acesso aos cuidados de saúde na comunidade brasileira de Lisboa. 2010. Dissertação (Mestrado). Faculdade de Ciências Médicas - Universidade Nova de Lisboa, Lisboa, 2010.

Recebido em: 25 de julho de 2013 Aceito em: 15 de dezembro de 2013 